\section{A expressão lexical da evidencialidade: reflexões sobre a dedução e a percepção de evento}

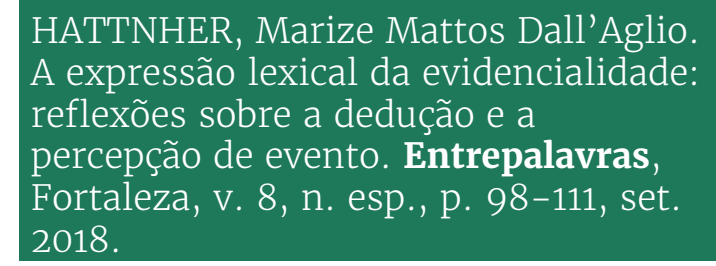

The lexical expression of evidentiality: reflection on deduction and event perception

Marize Mattos Dall'Aglio HATTNHER (Unesp) marize.hattnher@unesp.br

Recebido em: 17 de maio de 2018. Aceito em: 28 de jun. de 2018.

Resumo: Centrando meu interesse na identificação dos níveis de atuação das categorias evidenciais e, em especial, na existência de uma relação hierárquica entre elas, este artigo tem por objetivo principal verificar a validade das predições decorrentes da abordagem estratificada das categorias qualificacionais proposta pela Gramática Discursivo-Funcional para o estudo da expressão lexical da evidencialidade no português do Brasil. São analisados os diferentes usos de verbos evidenciais da língua portuguesa, enfocando especialmente os verbos polissêmicos que se prestam à expressão de dois subtipos evidenciais específicos, a percepção de evento e a dedução. Os resultados demonstram que as diferenças semânticas entre esses subtipos também se refletem na combinatória entre evidencialidade e tempo, comprovando a ordem hierárquica prevista pelo modelo para a expressão gramatical da evidencialidade.

Palavras-chave: Evidencialidade. Verbos evidenciais. Gramática DiscursivoFuncional. 
Abstract: The main goal of this paper is to verify the validity of the predictions derived from the stratified approach of the qualificational categories proposed by the Functional Discourse Grammar for the analysis of the lexical expression of evidentiality in Brazilian Portuguese. Different uses of evidential verbs are analyzed, with special attention to polysemic verbs that are used to express two specific evidential subtypes, the perception of an event and the deduction. The results show that the semantic differences between these subtypes are also reflected in the combinatorial between evidentiality and tense, confirming the hierarchical order predicted by the model to grammatical systems of evidentiality.

Keywords: Evidentiality. Evidential verbs. Functional Discourse Grammar.

\section{Introdução}

Entendendo a evidencialidade como a categoria responsável pela indicação da fonte da informação veiculada em um enunciado, propusemos, em trabalhos anteriores (HATTNHER, 2013; HENGEVELD; HATTNHER, 2015), uma nova tipologia dos evidenciais, identificada com base na análise de sistemas evidenciais gramaticais. Tendo como fundamento teórico a abordagem em camadas das categorias gramaticais adotada pela Gramática Discursivo-Funcional (GDF - HENGEVELD; MACKENZIE, 2008), identificamos três subtipos evidenciais alojados nas camadas semânticas do nível representacional (percepção de evento, dedução e inferência) e mais um subtipo alojado na camada do conteúdo comunicado, no nível interpessoal.

Uma vez que a GDF tem como princípio a organização hierárquica das unidades linguísticas, as categorias qualificacionais são definidas em termos de seu alcance semântico. Assim, considerando essa relação hierárquica, é possível formular um conjunto de predições relacionadas à interação entre as próprias categorias evidenciais e à interação entre a evidencialidade e outras categorias gramaticais.

De acordo com essas predições, a ordem dos marcadores de evidencialidade deve refletir a relação de escopo entre as diferentes categorias evidenciais. Além disso, essas categorias evidenciais devem apresentar comportamento diferente no que diz respeito às relações de escopo com outras categorias, tais como modalidade epistêmica, negação e tempo.

$\mathrm{Na}$ análise de 34 línguas indígenas brasileiras, todas com sistemas gramaticais de expressão da evidencialidade, algumas dessas predições puderam ser testadas e comprovadas. A existência, entre essas línguas, de diversos sistemas evidenciais complexos permitiu, especialmente, comprovar a ordem hierárquica entre os diferentes subtipos de evidencialidade. Essa hierarquia pôde ser comprovada pela coocorrência, pela ordem ou pelos valores coexpressos em morfemas portmanteau. 
v. 8 (esp.) 98-111 set. 2018

Em línguas em que a expressão da evidencialidade émarcadamente lexical, como é o caso do português, os recursos para a comprovação dessa hierarquia implicacional são mais escassos. Embora a hierarquia semântica se manifeste igualmente por meio de operadores gramaticais e modificadores lexicais, o caráter não obrigatório dos modificadores torna a análise da coocorrência pouco produtiva. Nesse sentido, um recurso mais eficaz, especialmente no caso dos verbos evidenciais, é a análise dos diferentes usos de um mesmo item, entendendo esses usos como resultado de um processo de gramaticalização.

No âmbito da GDF, a gramaticalização é vista como um processo no qual elementos linguísticos alargam o seu escopo (HENGEVELD, 2011). No caso de verbos evidenciais, isto significaria que os elementos evidenciais com escopo menor se desenvolvem em elementos evidenciais com escopo maior. Essa predição diacrônica tem consequências sincrônicas: se um verbo tem múltiplos significados evidenciais, esses significados devem ser de tipos de escopo contíguos em sua distribuição sincrônica.

Testar a validade dessa predição para a análise dos verbos evidenciais do português do Brasil implica, naturalmente, analisar a distribuição dos vários usos de verbos evidenciais polissêmicos, que expressam mais de um subtipo evidencial. O desafio, nesse caso, é avaliar em que medida os resultados obtidos segundo critérios formais e funcionais de base tipológica, assentados na análise de sistemas evidenciais gramaticais, podem ser aproveitados para o estudo dessas categorias em uma língua com expressão marcadamente lexical, que favorece a intersecção de valores semânticos. É em busca dessa avaliação que este trabalho se estrutura.

Nessesentido, aaplicabilidadedealguns resultados tipológicos obtidos na análise da expressão gramatical da evidencialidade será investigada na caracterização da expressão lexical de dois subtipos evidenciais específicos, muitas vezes tratados como um só pela literatura: a percepção de evento e a dedução. Para tanto, organizo este artigo da seguinte maneira: após uma breve apresentação dos subtipos evidenciais identificados por Hengeveld e Hattnher (2015) segundo o aparato teórico da Gramática DiscursivoFuncional, discuto as relações de escopo entre evidencialidade e tempo na língua portuguesa a partir dos resultados encontrados em Hattnher (2013) na análise de línguas indígenas do Brasil, com o intuito de tipificar a expressão da dedução e da percepção de evento. Por fim, exploro as consequências desse resultado de análise para a verificação da ordem hierárquica das categorias qualificacionais prevista pela GDF. 


\section{Evidencialidade na Gramática Discursivo-Funcional}

As categorias de tempo, aspecto, modalidade e evidencialidade são definidas na GDF em função das relações de escopo estabelecidas em termos de quatro diferentes camadas semânticas: i) o conceito situacional (f), ou a camada das propriedades, que não têm existência independente e se aplicam a outros tipos de entidades; ii) o estadode-coisas (e), que corresponde a uma situação real ou hipotética que o falante tem em mente; iii) o episódio (ep), que é uma combinação tematicamente coerente de estados-de-coisas que são caracterizados por unidade ou continuidade de tempo, localização e participantes; por fim, iv) a proposição (p), que é um construto mental, tal como conhecimentos, crenças e desejos.

Nessa perspectiva, como aponta Hengeveld (2011, p.582), "tempo, modo, aspecto e evidencialidade não são categorias unificadas na sua aplicação a essas camadas de organização semântica, mas elas se subdividem em diferentes subcategorias".

A maior variedade de subcategorias é encontrada na área da evidencialidade, como vou mostrar brevemente. A GDF considera a evidencialidade como uma categoria linguística que opera tanto no Nível Interpessoal (que dá conta das motivações pragmáticas da formulação linguística) como no Nível Representacional (que dá conta das motivações semânticas). Segundo a proposta de Hengeveld e Hattnher (2015), são quatro os subtipos evidenciais:

i. Reportatividade, que opera na camada do Conteúdo Comunicado no Nível Interpessoal, indica que o falante não está expressando seu próprio material cognitivo, mas está passando adiante a opinião de outros.

(1) Estudos feitos dizem que o produto não é cancerígeno. (internet)

ii. A Inferência, que opera na camada do Conteúdo Proposicional no Nível Representacional, indica que o Conteúdo Proposicional é inferido pelo falante com base em seu conhecimento prévio.

(2) Em princípio, parece que a definição de renda se apresenta bastante clara e precisa. (internet) 


\section{v. 8 (esp.)}

98-111 set. 2018

iii. Dedução, que opera no nível do Episódio e indica que a ocorrência de um episódio é deduzida pelo falante com base em uma evidência disponível; o falante não testemunha o próprio episódio, mas ele é capaz de deduzir sua ocorrência a partir da percepção de alguma evidência resultante.

(3) Estive olhando as fotos da Camila e percebi que ela varia os filtros de acordo com a cor da foto. (internet)

iv. Percepção de Evento, que opera na camada do Estado-deCoisas no Nível Representacional e indica se um evento foi ou não testemunhado pelo falante.

(4) Não estava frio, mas um pouco de vento trazia a brisa do mar. Senti o cheiro entrar nas minhas narinas. (internet)

Organizando os quatro subtipos evidenciais de acordo com a arquitetura hierárquica da GDF, temos:

Quadro 1 - Distribuição dos subtipos evidenciais segundo a arquitetura da GDF (adaptado de HENGEVELD; HATTNHER, 2015)

\begin{tabular}{|l|c|c|c|c|}
\hline NÍVEL & \multicolumn{3}{|c|}{ REPRESENTACIONAL } & INTERPESSOAL \\
\hline CAMADA & $\mathrm{e}$ & $\mathrm{ep}$ & $\mathrm{p}$ & $\mathrm{C}$ \\
\hline $\begin{array}{l}\text { SUBTIPO } \\
\text { EVIDENCIAL }\end{array}$ & $\begin{array}{c}\text { percepção de } \\
\text { evento }\end{array}$ & dedução & inferência & reportatividade \\
\hline
\end{tabular}

Como apontado por Hengeveld e Hattnher (2015), a colocação da reportatividade na camada do Conteúdo Comunicado é coerente com o fato de ele ser usado para qualquer conteúdo transmitido em um ato de fala. A colocação da inferência na camada do Conteúdo Proposicional é coerente com o seu estatuto mental. Uma vez que a dedução está ligada à percepção de uma evidência no momento da fala, a colocação desse subtipo na camada do Episódio é coerente com o fato de o Episódio ser localizado em tempo absoluto. Uma vez que na percepção de evento a observação está ligada à ocorrência de um Estado-de-Coisas, a colocação desse subtipo é coerente com o fato de um Estado-de-Coisas ser localizado em tempo relativo. 
Como se vê, a categoria de tempo também é distribuída em diferentes camadas semânticas que dão conta das distinções de tempos absolutos (como o passado e o futuro), que localizam (uma série de) estados-de-coisas no tempo em relação ao momento da fala, e as distinções de tempos relativos (tais como anterior e posterior), que localizam no tempo um único estado-de-coisas em relação a um outro. É essa visão estratificada da categoria de tempo que se mostra especialmente relevante para a caracterização dos subtipos evidenciais aqui analisados, como se verá a seguir.

\section{Evidencialidade e tempo}

Como já foi dito, a aceitação da distribuição hierárquica das categorias qualificacionais implica a pressuposição de que os subtipos evidenciais se comportam de maneira diferente no que diz respeito às relações de escopo que estabelecem com outras categorias gramaticais. Assim, passo a analisar a relação que se estabelece entre evidencialidade e tempo, com o propósito específico de buscar traços que caracterizem a expressão lexical da dedução e da percepção de evento, dois subtipos evidenciais que frequentemente são vistos como um só. Mais especificamente, quero verificar se a hipótese defendida por Hattnher (2013), com base na análise de operadores gramaticais de evidencialidade, também se aplica à expressão lexical dessa categoria por meio dos verbos evidenciais da língua portuguesa.

Conforme descrito em Hattnher (2013, p.51), é a semântica do evidencial que determina as opções no sistema temporal. Sendo assim, o esperado é que as diferenças semânticas entre percepção de evento e dedução também se reflitam na combinatória de tempo entre a matriz e a encaixada, bem como na forma finita ou não finita da encaixada.

A dedução, de acordo com Hengeveld e Hattnher (2015, p. 486), indica que a informação que o falante apresenta é deduzida com base em uma evidência perceptual, o que significa que

a dedução envolve necessariamente pelo menos dois estadosde-coisas relacionados: o falante deduz a ocorrência de um estado-de-coisas, o deduzido, a partir de outro estado-decoisas, o percebido.

O fato de, na semântica da dedução, haver dois eventos envolvidos traz alguma especificidade à sua combinatória com tempo, como Fleck (2003, p.405) aponta em sua definição de dedução: 
v. 8 (esp.)

98-111

set.

2018

O que se entende por inferência [dedução, nos termos da GDF] é que o falante não presenciou o evento em si, mas é capaz de deduzir a sua ocorrência via alguma evidência resultante. Mais uma vez, vemos o papel do tempo na definição de distinções evidenciais na medida em que esta condição impede, então, referência a eventos que estão ocorrendo no momento do ato de fala ou a eventos futuros. ${ }^{1}$ (FLECK, 2003, p.405).

Por sua vez, a expressão da percepção de evento indica que um estado-de-coisas foi atestado pelo falante. Isso significa que o tempo dos dois eventos, o expresso pelo verbo evidencial e o evento experienciado expresso pela oração completiva têm de ser simultâneos. Espera-se, dessa forma, que essas características sejam expressas pela correlação temporal, afetada pelo tipo de evidencialidade expressa pelo predicador.

Vejamos, então, quais são as determinações semânticas e formais do predicado matriz evidencial de percepção de evento e dedução.

Como já dito, por meio da evidencialidade de percepção de evento, o falante indica que um estado de coisas foi atestado por ele. Ou seja, necessariamente o tempo do evento expresso pelo predicador verbal e o tempo do evento experienciado expresso pela oração completiva têm de ser simultâneos, como em (5), no presente, ou (6), no passado:

(5) Além do barulho contínuo e monótono do trem sobre os trilhos, ainda ouço crianças chorando, gente conversando na madrugada, eu sem conseguir dormir e sem vontade nem de tentar divisar possíveis paisagens noturnas. (internet)

(6) Estava passando pela ponte e vi a mulher rolando no barranco e caindo de cabeça. (internet)

Nesses dois casos, a referência temporal da oração matriz se estende para a oração completiva que se apresenta na forma não finita. Mesmo nos casos em que a completiva se apresenta desenvolvida, o tempo das duas orações deve ser simultâneo, como em:

(7) - Vilu, eu vi que você estava chorando no banco de trás do carro.

- Ai Leon, eu não queria que você tivesse visto, me desculpa

\footnotetext{
${ }^{1}$ What is meant by "inferential" here is that the speaker did not witness the event itself, but is able to deduce its occurrence via some resulting evidence. Again, we see the role of tense in defining inferential distinctions in that this condition then precludes reference to events that are occurring at the time of the speech act or to future events".
} 
É essa necessidade de concomitância entre os dois eventos, o percebido e o relatado, que impede as completivas encaixadas em predicado de percepção de evento de ocorrerem com o tempo futuro, uma vez que o momento da percepção do evento tem de estar acessível para o falante. É essa mesma característica que justifica a preferência pelas completivas não-finitas com verbos que expressam evidencialidade de percepção de evento. Observem-se, agora, as seguintes ocorrências desses mesmos verbos com complementos oracionais na forma finita:

(8) Eu vi que ele tinha ido embora. (internet)

(9) Mexi no celular do meu namorado e vi que ele me trai. E agora? (internet)

Nesses casos, o evento expresso pela oração encaixada não é o evento percebido pelo falante, mas é um evento deduzido com base na percepção de alguma evidência.

Embora haja sempre dois eventos envolvidos na informação apresentada como dedução, a maioria das línguas que apresentam expressão gramatical da evidencialidade expressam apenas um desses eventos, o deduzido, deixando implícita a evidência percebida pelo falante: "a ausência dele" em (8) e "a troca de mensagens" em (9), por exemplo.

Essa omissão do evento percebido é bastante comum nas 64 línguas indígenas analisadas em Hattnher (2013). Em apenas uma delas, o sabanê, a dedução ocorre necessariamente em sentenças anteriores a outra sentença com uma evidência sensorial expressa.

Da mesma forma, em português, a expressão lexical da dedução também pressupõe a ocorrência de um estado-de-coisas percebido que, no entanto, fica implícito. Nesses casos, o tempo presente da oração completiva implica necessariamente uma distância temporal ou espacial entre o evento relatado e o momento do relato, e uma concomitância entre a detecção da evidência e o evento relatado. Em (8) acima, o falante não estava no mesmo tempo e espaço em que "ele foi embora", caso contrário ele poderia usar um evidencial de deteç̧ão de evento (eu vi ele ir embora), assim como o evento deduzido em (9), "ele me trair" não ocorreu no mesmo tempo e espaço do evento percebido "ver as mensagens no celular". O passado envolve necessariamente uma distância temporal, uma vez que os eventos deduzidos são sempre vistos como concluídos. 
v. 8 (esp.) 98-111 set. 2018

Nos mesmos moldes do que ocorre com os evidenciais gramaticais descritos por Hattnher (2013), podemos considerar que, na expressão lexical de um evento como deduzido, há sempre três eventos envolvidos - a percepção de uma evidência, a dedução de um evento e o relato do evento deduzido - as combinações lógicas desses intervalos de tempo podem ser de dois tipos:

Tipo 1: a percepção da evidência é anterior ao evento deduzido, ambos anteriores ao momento da fala:

(10) Vi que ela voltou para casa (o falante não a viu retornando, mas ele viu a garota em sua casa)

$\begin{array}{ccc}\left(\mathrm{e}_{\mathrm{i}}\right) & \left(\mathrm{e}_{\mathrm{j}}\right) & \left(\mathrm{e}_{\mathrm{k}}\right): \\ & \mathrm{ME}\end{array}$

onde:

$\left(e_{\mathrm{i}}\right)$ = a percepção do evento no passado: o falante viu a garota em casa

$\left(e_{j}\right)$ = a dedução de um outro evento no passado: o falante deduz que a garota voltou;

$\left(e_{k}\right)=o$ relato do evento deduzido no momento da fala: o falante diz que a garota voltou para casa.

Tipo 2: A percepção de uma evidência é anterior ao evento deduzido que é simultâneo ao momento da fala:

(11) Eu vejo que meu pai está carpindo o terreno (o falante sabe disso porque seu pai e a enxada dele estão desaparecidas).

A representação desses três eventos em uma linha do tempo seria:

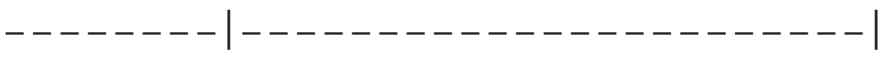

$\left(\mathrm{e}_{\mathrm{i}}\right)$

$\left(e_{j}\right)$

$\left(e_{k}\right)$ :

ME 
Onde:

$\left(\mathrm{e}_{\mathrm{i}}\right)$ = percepção de um evento no passado: o falante viu que seu pai e suas ferramentas desapareceram

$\left(e_{j}\right)=$ a dedução de outro evento simultâneo ao momento da enunciação: o falante deduz que seu pai está carpindo o campo.

$\left(e_{k}\right)=$ o relato de um evento deduzido no momento da fala: o falante diz que seu pai está carpindo o campo.

Um resultado importante dessa dupla representação de tempo, e que confirma os resultados da análise da expressão gramatical da evidencialidade apresentada em Hattnher (2013), é que a diferença semântica fundamental entre a percepção de eventos e dedução estabelecida na GDF pode ser facilmente percebida, mesmo quando não há operadores de tempo relativo explícitos (anterioridade, simultaneidade ou posterioridade) como o caso aqui analisado: o evento percebido (ei) é sempre estabelecido em relação ao evento deduzido (ej), o que confirma a localização temporal relativa como característica fundamental dos eventos. Embora o evento percebido e o deduzido estejam intrinsecamente relacionados (ou talvez exatamente por causa disso), o padrão é ter apenas o evento deduzido expresso no relato, enquanto o evento percebido fica implícito. Mas, mesmo quando há apenas um marcador de tempo, o ponto de referência da sentença com o evidencial de dedução é sempre o momento da enunciação, o que confirma a localização em tempo absoluto como a característica básica dos episódios.

Apenas para comparar, a representação de um evento percebido pelo falante pressupõe sempre a simultaneidade entre a ocorrência do evento e a sua percepção pelo falante, como se vê em:

(12) Eu vi a garota entrar em casa./Vi que a garota entrou em casa.

$\left(\mathrm{e}_{\mathrm{i}}\right)$
$\left(\mathrm{e}_{\mathrm{j}}\right)$

OU

(13) Vejo a garota entrando/entrar em casa./ Vejo que a garota está entrando em casa. 


\section{v. 8 (esp.)}

98-111 set. 2018

ME

Observa-se, desse modo, que a indicação de tempo e a forma não-finita (que só se aplica aos verbos de percepção) ou finita da oração completiva está diretamente relacionada ao valor semântico do predicador, que pode ser entendido como uma expressão de percepção de evento ou de dedução.

Entretanto, é importante ressaltar que, dada a polissemia dos verbos evidenciais, é possível que os mesmos verbos que servem para a expressão da dedução e da percepção de evento sirvam, também, à expressão da inferência e até da reportatividade, casos em que os tempos da oração matriz e da encaixada também não serão simultâneos. Nesses casos, a diferença entre os subtipos é feita não pela relação da evidencialidade com o tempo, mas pela natureza semântica do complemento: um conteúdo comunicado no caso dos verbos reportativos e uma proposição no caso dos verbos inferenciais.

É o que demonstra Vendrame (2010) para os verbos ver, ouvir e sentir. Segundo a autora, esses verbos podem expressar os seguintes subtipos evidenciais:

Quadro 2 - Verbos de percepção por tipo de evidencialidade, camada e nível da GDF (VENDRAME, 2010, p.134)

\begin{tabular}{|l|c|c|c|c|}
\hline \multirow{4}{*}{$\begin{array}{l}\text { Verbos de } \\
\text { percepção }\end{array}$} & $\begin{array}{c}\text { Evidencialidade } \\
\text { Reportativa }\end{array}$ & $\begin{array}{c}\text { Evidencialidade } \\
\text { Inferida }\end{array}$ & $\begin{array}{c}\text { Evidencialidade } \\
\text { Deduzida }\end{array}$ & $\begin{array}{c}\text { Evidencialidade } \\
\text { direta }^{2}\end{array}$ \\
\cline { 2 - 5 } & $\begin{array}{c}\text { Conteúdo } \\
\text { Comunicado }\end{array}$ & $\begin{array}{c}\text { Conteúdo } \\
\text { Proposicional }\end{array}$ & Episódio & $\begin{array}{c}\text { Estado-de- } \\
\text { coisas }\end{array}$ \\
\hline Ver & + & + & + & + \\
\hline Ouvir & + & + & + & + \\
\hline Sentir & - & + & + & + \\
\hline
\end{tabular}

Somados às considerações sobre a relação entre tempo e evidencialidade na análise da dedução e da percepção de evento, os resultados de Vendrame (2010) também servem à comprovação da ordem hierárquica entre os diferentes subtipos de evidencialidade. Como já dito, a análise dos diferentes usos de um mesmo verbo evidencial

\footnotetext{
${ }^{2}$ Evidencialidade de percepção de evento, nos termos da GDF.
} 
pode ser entendida como uma consequência sincrônica de um processo diacrônico de gramaticalização, em que os elementos evidenciais com escopo menor se desenvolvem em elementos evidenciais com escopo maior, o que implica, necessariamente, que os múltiplos sentidos de um verbo evidencial devem ser de tipos de escopo contíguos em sua distribuição sincrônica.

Os resultados obtidos por Hattnher e Hengeveld (2016) mostraram que a teoria da gramaticalização desenvolvida dentro do contexto da GDF faz as previsões corretas sobre a distribuição sincrônica de verbos modais em todas as camadas, constituindo-se como um caminho promissor para pesquisas sobre os meandros da gramaticalização das categorias temporais, modais, aspectuais e evidenciais.

Com base nesse raciocínio, é possível predizer a seguinte trajetória de mudança no campo da evidencialidade:

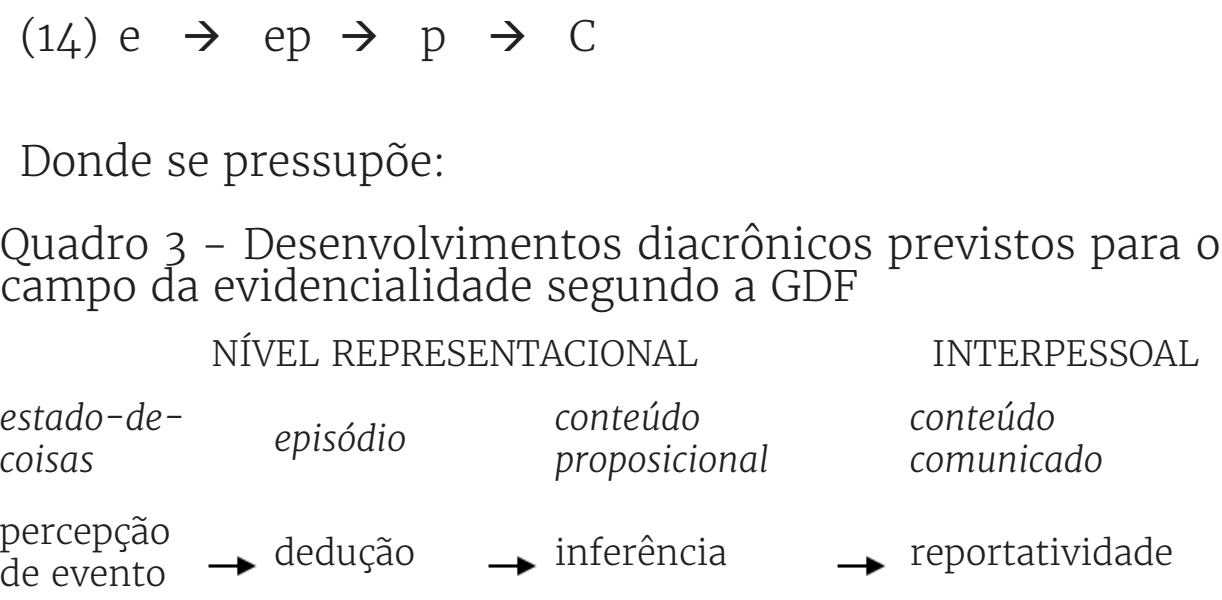

Como resultado desse percurso hipotético de mudança, assumimos que os vários significados de um verbo evidencial devem ocupar partes contíguas deste percurso. Testando essa predição com o verbo ver, descrito por Vendrame (2010) como um dos verbos de percepção mais polissêmicos da língua portuguesa, temos:

(15) Aos poucos, ele foi abrindo a janela e eu vi que o menino estava dentro do carro. (internet) - percepção

(16) Pelos seus gritos, vejo que involuntariamente o incomodei. Peço desculpa, não era a intenção. (internet) dedução

(17) 'Não vejo que o governo vá cair por conta de Lava Jato', diz conselheiro de Temer. (internet) - inferência 
v. 8 (esp.)

98-111

set.

2018

(18) Olha, primeiro eu não acreditei quando eu soube, quando eu vi na Folha de São Paulo que o meu livro tinha sido um dos mais vendidos. (internet) - reportativo

Resultado semelhante pode ser aferido para outros verbos evidenciais, tais como ouvir, sentir, achar, perceber e observar, que expressam subtipos evidenciais contíguos nas camadas semânticas do nível representacional da GDF.

\section{Considerações finais}

Com o objetivo de verificar a pertinência da distinção entre os subtipos evidenciais alojados nas camadas do estado-de-coisas e do episódio para a descrição de sistemas evidenciais lexicais, propusemos algumas reflexões sobre a relação entre tempo e evidencialidade nas orações encaixadas em verbos evidenciais. As análises mostraram que a simultaneidade entre a ocorrência do evento e a sua percepção pelo falante caracteriza a percepção de evento, ao passo que a dedução implica necessariamente uma distância temporal ou espacial entre o evento relatado e o evento percebido.

Esses resultados, ainda que não sejam assentados em descrição de um córpus específico, demonstram a adequação da adoção de um modelo teórico de descrição do ato de discurso em níveis e camadas, como é o caso da Gramática Discursivo-Funcional, para a análise de fenômenos complexos como a evidencialidade mesmo em sua expressão lexical, cuja análise necessariamente envolve fatores pragmáticos e sintático-semânticos interligados.

Agradecimentos: Esta pesquisa foi financiada pelo CNPq (Proc. 311626/2015-7)

\section{Referências bibliográficas}

FLECK, D. A Grammar of Matses. Ph.D, Rice University, 2003.

HATTNHER, M. M. D. A.; HENGEVELD, K. The grammaticalization of modal verbs in Brazilian Portuguese: A synchronic approach. Journal of Portuguese Linguistics, v. 15, n. 1, 2016, p. 1-14. http://dx.doi.org/10.5334/jpl.1.

HATTNHER, M. M. D. A. The interaction between tense and evidentials of event perception and deduction in Brazilian Native languages. In: MACKENZIE, J. L.; OLBERTZ, H. (Ed.) Casebook in Functional Discourse Grammar. $1^{\mathrm{a}}$ ed. Amsterdam: John Benjamins, p. 39-66, 2013. 
HENGEVELD, K. The grammaticalization of tense and aspect. In: BERND, Heine; NARROG, Heiko (Ed.). The Oxford Handbook of Grammaticalization. Oxford: Oxford University Press, p. 580-594, 2011.

HENGEVELD, K.; HATTNHER, M.M.D.A. Four types of evidentiality. Linguistics, V. 53, p. 479-524, 2015.

HENGEVELD, K.; MACKENZIE, L. Functional Discourse Grammar. A typologically-based theory of language structure. Oxford: Oxford University Press, 2008.

VENDRAME, V. Os verbos ver, ouvir e sentir e a expressão da evidencialidade em língua portuguesa. $173 \mathrm{f}$. Tese (Doutorado em Estudos Linguísticos) Instituto de Biociências, Letras e Ciências Exatas, UNESP, São José do Rio Preto, 2010. 